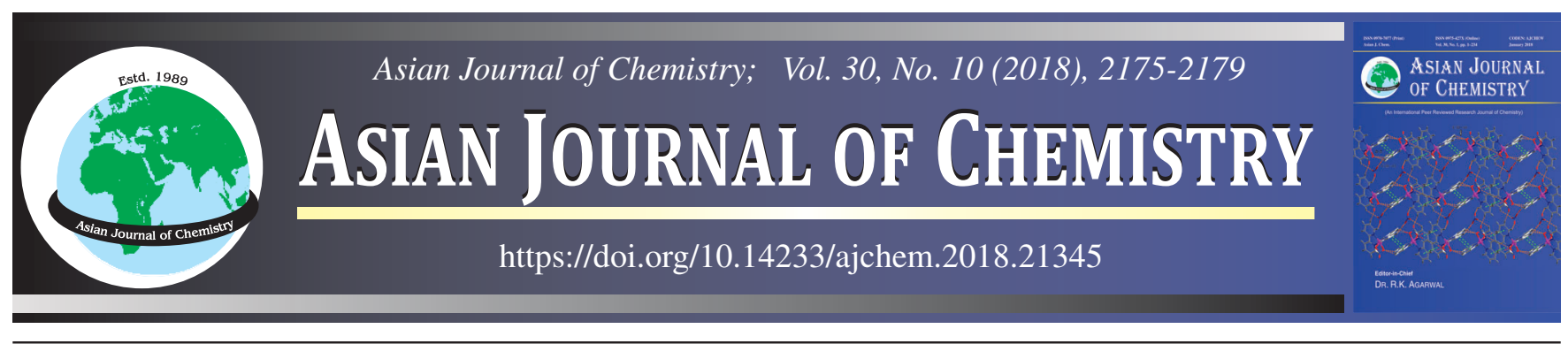

\title{
Kinetic Study for Reduction of Organic Dye using Graphene Oxide Supported Ru-Ag Nanoparticles Catalyst
}

\author{
Perumal Andal*, S. TAmiJselvy and P. IndRapriyatharesini
}

Department of Chemistry, School of Basic Sciences, Vels University, Pallavarm, Chennai-600 117, India

*Corresponding author: E-mail: andalprithu.sbs@velsuniv.ac.in

Received: 23 March 2018;

Accepted: 16 August 2018;

Published online: 31 August 2018;

AJC-19039

The kinetic effect of organic pollutants present in water such as commercial dyes, namely malachite green, rhodamine B, were studied. The kinetic effects of reduction of initial dye concentration using Ru-Ag NPs and substrate were determined. From the $\mathrm{K}_{\mathrm{obs}}$ results, the order of rate constant of $\mathrm{Ag}$, Ru and Ru-Ag NPs were studied under pseudo-first order reaction condition. The apparent rate constant for the reduction of rhodamine $\mathrm{B}$ and malachite green by using Ru-Ag NPs catalyst, $\mathrm{k}_{\mathrm{obs}}$ was initiated to be higher than other mono metallic nanoparticles catalyst. The reason for increased $\mathrm{k}_{\mathrm{obs}}$ noticed in Ru-Ag NPs may be attributed due to the size distribution of the Ru-Ag NPs catalyst which is found to be relatively smaller, viz. $10 \mathrm{~nm}$ than another catalyst. The result used for calculating the pseudo first order of miscellaneous dye-containing wastewaters. It was also found that the decolourization of the dyes undergoes a fast reaction than the mineralization

Keywords: Graphene oxide, Malachite green, Rhodamine B, Ru-Ag nanoparticles, Kinetic studies, Reduction.

\section{INTRODUCTION}

Textile industries releases enormous quantity of waste water containing high concentration of dyes [1]. The non-biodegradable nature dye baths causes severe environmental troubles [2]. Rhodamine $\mathrm{B}$ is one of the predominant xanthene cationic dyes, is generally used in industry as a dye for paper, silk, wool, jute leather, cotton. The xanthene dyes (rose bengal, eosin Y and rhodamine $6 \mathrm{G}$, etc.) are used as fluorescent markers in constitutional nanosized studies, photosensitizers and laser dyes. They have long been familiar to be harmful, to insects (insecticide). They are toxic if consumed by human and animals and cause irritation to the skin, eyes and lung [3,4]. They described the utilization of Plectranthus amboinicus leaf extract [5] as reducing agent for the synthesis of AgNPs as a catalysts which shows high antimicrobial activity. The first time synthesis of $\mathrm{SnO}_{2} \mathrm{NPs}$ using Plectranthus amboinicus leaf extract as reducing agent were reported here as a reference [5].

In the presence of $\mathrm{NaBH}_{4}$, electron transfer occurs due to the catalytic reductive degradation of organic dye molecules by metal nanoparticles (MNPs), which is responsible for reducing speed of the reaction [6-11].
Rhodamine B and malachite green [12] are basic dyes that have become more important in the textile industry due to their more rigid structures than other organic dyes. Their cationic structure is best applied to anionic fabrics which contain negative charges. The dyes are brilliant and most fluorescent among other synthetic dyes. In addition, the chromophore in their structures is known to be carcinogenic. Rhodamine B and malachite green have been extensively used around the world in silk, wool and cotton dyeing industries. Recently, increasing use of these dyes has been linked to increase risks of cancer. A number of methods have been developed in recent years for their degradation and treatment

Photocatalytic effect of organic compounds such as methyl green and rhodamine $\mathrm{B}$ in water is noticeable due to the sensitive, biological collision of miscellaneous industrial and agricultural pollutants $[13,14]$. The photocatalytic activities of homogeneous or heterogeneous reactions depends up on the nature of their reactants and materials (semiconductors). An example of heterogeneous photocatalytic reaction using semiconductor materials $\mathrm{TiO}_{2}$ and $\mathrm{ZnO}$, observed by photodecomposition of organic pollutant molecules into less harmful compounds [15-19].

This is an open access journal, and articles are distributed under the terms of the Creative Commons Attribution-NonCommercial 4.0 International (CC BY-NC 4.0) License, which allows others to copy and redistribute the material in any medium or format, remix, transform, and build upon the material, as long as appropriate credit is given and the new creations are licensed under the identical terms. 
Graphene sheets can be synthesized by three major methods, such as mechanical exfoliation, chemical vapour deposition (CVD) onto metal or Si substrates and the chemical, electrochemical, or thermal reduction of graphene oxide. Chemical vapour deposition method is most successful for the mass production of graphene and can be used to fabricate immense areas of graphene while restricting the number of inadequacy [20].

In recent years, many research works focusing on the degradation mechanism of rhodamine B [21-26], most of them are problematic under the mechanism of visible illustration. In this current study, Ru-Ag NPs are used as a catalyst for the reduction of organic dyes namely rhodamine $\mathrm{B}$ and malachite green.

\section{EXPERIMENTAL}

Graphite powder (SRL), silver nitrate (SRL), ruthenium trichloride hydrate (SRL), potassium dichromate (SRL), rhodamine B and malachite green (SRL), sodium borohydride (SRL), double distilled water were analytical grade of $99 \%$ purity and used as received.

UV-visible spectrophotometer: The UV-visible spectra were measured on Perkin Elmer Lamda-35 instruments with UV Win-lab software. The measurements were carried out in the wavelength range of 200-800 $\mathrm{nm}$ under ambient conditions.

The comparative catalytic activity of mono and bimetallic nanoparticles catalysts were examined by conducting the reduction of rhodamine $\mathrm{B}$ and malachite green is a model reaction keeping under identical pseudo-first order experimental condition. The reaction was carried out individually in a standard quartz cuvette with $1 \mathrm{~cm}$ path length to which $2.5 \mathrm{~mL}$ water, $0.25 \mathrm{~mL}$ rhodamine $\mathrm{B}$ and malachite green $(1$ $\mathrm{mmol}), 0.25 \mathrm{~mL} \mathrm{NaBH}_{4}(100 \mathrm{mmol})$ and $5 \mathrm{mg}$ of respective catalyst was added. After mixing the respective solution the corresponding cuvette was placed in a UV-visible spectrometer maintaining the temperature at $27{ }^{\circ} \mathrm{C}$. The occurrence of the reaction was recorded in the range from $200-700 \mathrm{~nm}$. The decreasing trend of characteristic peak was recorded at regular intervals of time ( $5 \mathrm{~min}$ ) and the same has been used for the calculation of pseudo first order rate constant. The pseudo first rate constant was calculated using the formula.

$$
\mathrm{K}_{\text {obs }}=\ln \left[\left(\mathrm{A}-\mathrm{A}_{0}\right) /\left(\mathrm{A}-\mathrm{A}_{\mathrm{t}}\right)\right] / \mathrm{t}
$$

where, $\mathrm{A}=$ absorbance at infinity time, $\mathrm{A}_{0}=$ initial absorbance, $\mathrm{A}_{\mathrm{t}}=$ absorbance at different time $\mathrm{t}$.

The comparative $\mathrm{K}_{\mathrm{obs}}$ values are calculated for another one bimetallic and three mono metallic nanoparticles catalysts. The observed $\mathrm{K}_{\mathrm{obs}}$ value reveals that the Go-Ru/Ag NPs catalyst is found to be superior catalysts compare to other bimetallic and mono metallic nanoparticles.

Graphite oxide was prepared by the using Hummer method and exfoliated into graphene oxide by sonication in water. These graphene oxide supported mono and bimetallic nanoparticles catalyst were prepared by chemical reduction method. The first catalyst viz., Ru-Ag bimetallic nanoparticles was prepared by taking in a $100 \mathrm{~mL}$ round bottom flask, typically, $0.06 \mathrm{~mm}$ of ruthenium trichloride hydrate to which potassium tetrachloroargantate was added. Sonicated $(5 \mathrm{mg}$ and $30 \mathrm{~mL}$ water for $30 \mathrm{~min}$ ) grapheme oxide was added to the above mixture and the reaction was stirred for further $2 \mathrm{~h}$ at $120^{\circ} \mathrm{C}$. Finally $0.1 \mathrm{M}$ sodium borohydride solution was added to the reaction mixture. The resulting solution was cooled and centrifuged at $2500 \mathrm{rpm}$. The water and ethanol were used for further purification. The collected product was dried at $70{ }^{\circ} \mathrm{C}$ in vacuum oven.

In a similarly manner, by adopting the same quantity of the reagents and experimental procedure the bimetallic and mono metallic nanoparticles catalysts viz., $\mathrm{Ru} / \mathrm{Ag}, \mathrm{Ru}$ and AgNPs were also prepared. The metal precursors for $\mathrm{Ru} / \mathrm{Ag}$, $\mathrm{Ru}$ and $\mathrm{AgNPs}$ were $\mathrm{AgNO}_{3}$ and $\mathrm{RuCl}_{3} \cdot \mathrm{H}_{2} \mathrm{O}$ solution. The reduction of $\mathrm{Ag}^{+} / \mathrm{Ru}^{3+}, \mathrm{Ag}^{+} / \mathrm{Ru}^{3+}$ to $\mathrm{Ru} / \mathrm{Ag}, \mathrm{Ru}$ and $\mathrm{AgNPs}$ was noticed through the change of colour.

\section{RESULTS AND DISCUSSION}

It is well known that the research on catalysis is proved to be a essential subject and this achievement in turn can strengthen the economy of the industries. In the last two decades the research interest on development of homogeneous nanoparticles catalyst has expand tremendously owing to its and unexplainable advantages. To synthesis homogeneous mono/bimetallic nanoparticles catalysts, one should need an appropriate template to stabilize/encapsulate the metal nanoparticles. Further in the preparation of homogeneous metal nanoparticles as catalyst, identification of template/stabilizing agent is proved to be a bigger task.

Kinetic study for the reduction of rhodamine B using graphene oxide supported Ru-Ag NPs catalyst: In order to realize the effect of $\left[\mathrm{NaBH}_{4}\right]$, [substrate] and [catalyst] in the reduction process of organic dyes, the catalyst viz., $\mathrm{Ru}-\mathrm{Ag}$ NPs was employed and studied under pseudo-first order reaction condition. The kinetics reduction reaction of the dyes was measured between the absorbance of the product with decreasing trend $544 \mathrm{~nm}$ against the time through UV-visible spectrophotometer. From the observed rate constants, it is understood that the $\left[\mathrm{NaBH}_{4}\right]$, [substrate] and [Catalyst] has been largely influenced the $\mathrm{k}_{\mathrm{obs}}$ in the reduction of organic dyes substrate.

Effect of [substrate]: The substrate concentration varied from 0.8 to $1.4 \mathrm{~mm}$ at constant temperature $27^{\circ} \mathrm{C}$ and the experiments were performed by maintaining the other parameters as constant. The rate constants are calculated from the plot $2+\log \left(\mathrm{A}-\mathrm{A}_{\mathrm{t}}\right) v s$. time and the calculated values are given in Fig. 1. The observed rate constants are decreased invariably on increasing the dyes are given in Table-1 (Fig. 2). The decreasing trend of rate constant is due to lesser availability of $\mathrm{BH}_{4}{ }^{-}$in aqueous phase and thus minimizing the formation of product.

Effect of $\left[\mathrm{NaBH}_{4}\right]$ : The effect of concentration of $\mathrm{NaBH}_{4}$ for reduction of rhodamine $\mathrm{B}$ was studied in the range from 60 to $110 \mathrm{~mm}$ keeping the other parameters as constants. From the plot of $2+\log \left(\mathrm{A}-\mathrm{A}_{\mathrm{t}}\right) v s$. time, the pseudo-first order rate

\section{TABLE-1}

\begin{tabular}{cccc}
\hline$[\mathrm{Rh}-\mathrm{B}](\mathrm{mm})$ & {$\left[\mathrm{NaBH}_{4}\right](\mathrm{mm})$} & {$[$ Catalyst $](\mathrm{mg})$} & $\mathrm{K}_{\mathrm{obs}} \times 10^{-3}\left(\mathrm{~s}^{-1}\right)$ \\
\hline 0.8 & 100 & 5 & 2.6940 \\
1.0 & 100 & 5 & 1.6680 \\
1.2 & 100 & 5 & 1.3615 \\
1.4 & 100 & 5 & 1.2343 \\
\hline
\end{tabular}




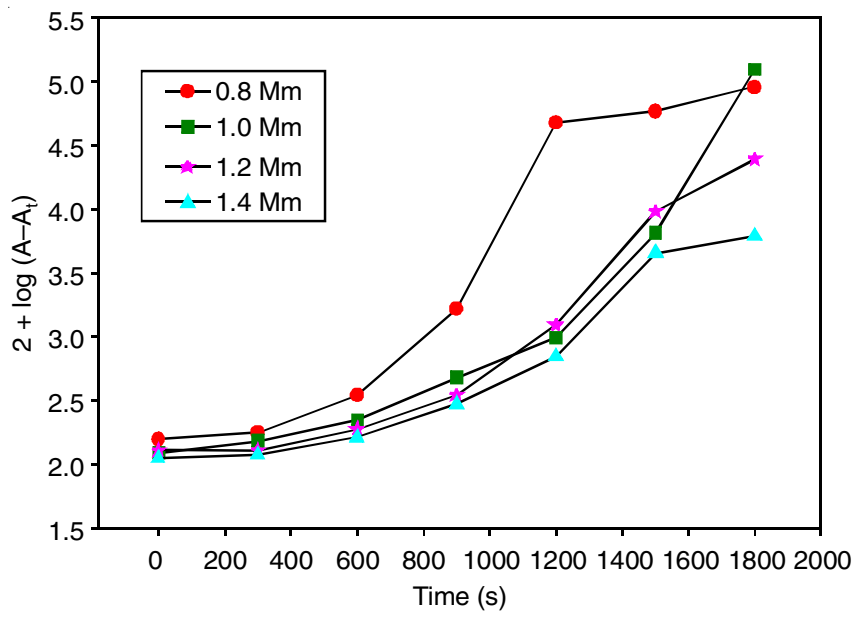

Fig. 1. Plot of $2+\log \left(A-A_{t}\right)$ vs. time

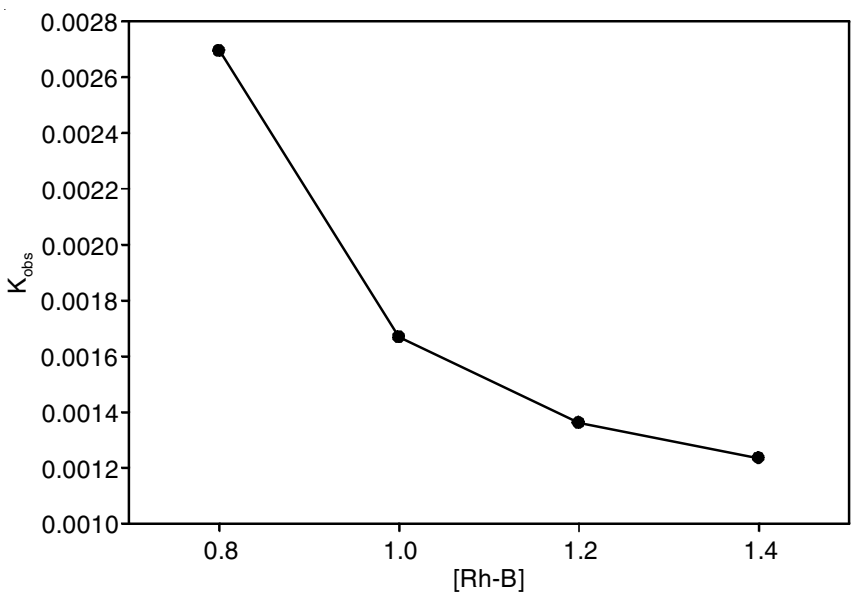

Fig. 2. $\mathrm{K}_{\mathrm{obs}} v s$. [Rh-B]

constants were evaluated and the corresponding plots were depicted in Fig. 3. The observed rate constants increased with the increase in the concentration of $\mathrm{NaBH}_{4}$ and presented in Table-2 and the plots are depicted in Fig. 4. On increasing the $\left[\mathrm{NaBH}_{4}\right]$, the adsorption of $\mathrm{BH}_{4}^{-}$ions onto the nanoparticles surfaces also parallely increases, as a result, the relay of electrons from $\mathrm{BH}_{4}^{-}$(donor) to the rhodamine $\mathrm{B}$ (receptor) increases. It is worth to state that under the fixed concentration of $\mathrm{NaBH}_{4}$ the reduced product viz., organic dyes remains non-oxidized, since the liberated hydrogen eliminates the air hence prevents the oxidation. In addition to this the evolved hydrogen bubbles from the catalyst surface helps in mixing of the solution and thus offering the favourable conditions to increase the reaction rates.

Effect of catalysts: Similarly, in the case of change in the concentration of the catalyst, the $\mathrm{k}_{\mathrm{obs}}$ were found to increases with respect to the concentration of catalyst irrespective of organic dyes used. The effect of graphene oxide-Ru-Ag NPs

\begin{tabular}{cccc}
\multicolumn{5}{c}{ TABLE-2 } \\
\hline$[\mathrm{Rh}-\mathrm{B}](\mathrm{mm})$ & {$\left[\mathrm{NaBH}_{4}\right](\mathrm{mm})$} & {$[$ Catalyst $](\mathrm{mg})$} & $\mathrm{K}_{\mathrm{obs}} \times 10^{-3}\left(\mathrm{~s}^{-1}\right)$ \\
\hline 1.0 & 60 & 5 & 1.36140 \\
1.0 & 80 & 5 & 1.46140 \\
1.0 & 100 & 5 & 1.66179 \\
1.0 & 110 & 5 & 3.17710 \\
\hline
\end{tabular}

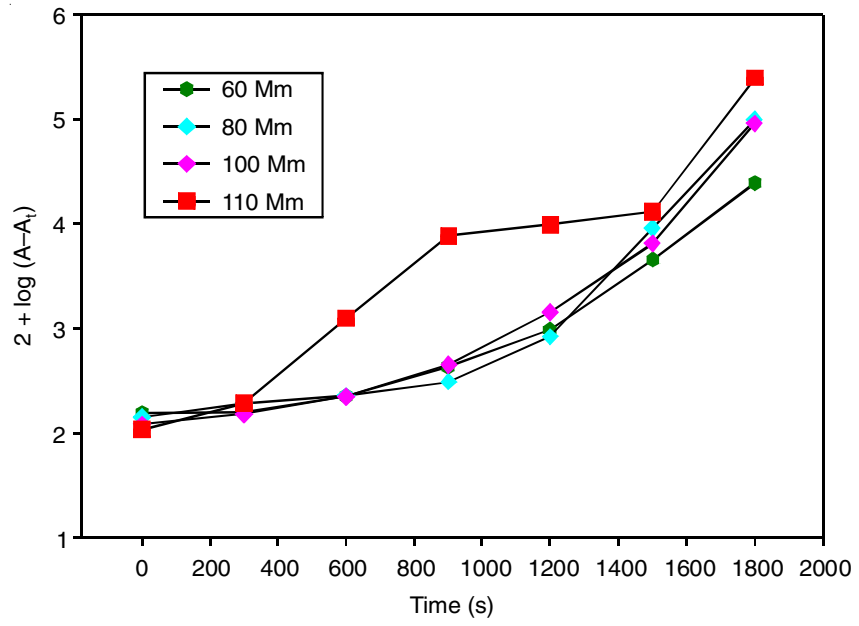

Fig. 3. Plot of $2+\log \left(A-A_{t}\right)$ vs. time

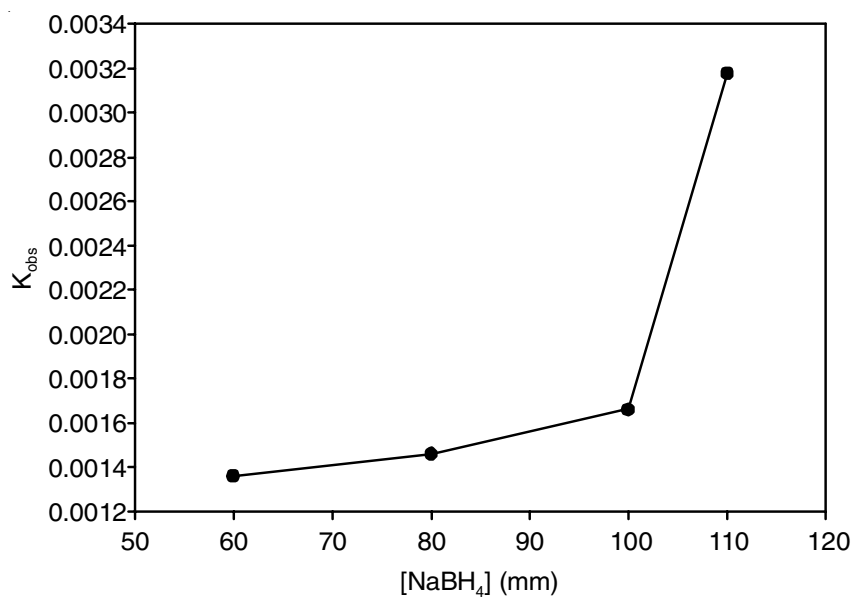

Fig. 4. $\mathrm{K}_{\mathrm{obs}}$ vs. $\left[\mathrm{NaBH}_{4}\right]$

was performed by varying the concentration of the catalyst from 3 to $8 \mathrm{mg}$ which is shown in Fig. 5, keeping the other parameters constant. The plot derived from observed rate constant against the amount of catalyst was shown in Table-3. From this plot, it has been understood that the amount of catalyst and the rate constant are parallel to each other are given in Fig. 6. It has been obviously known fact, that at higher concentration of the catalyst, the active sites of nanoparticles is also high that enhances the rate constant.

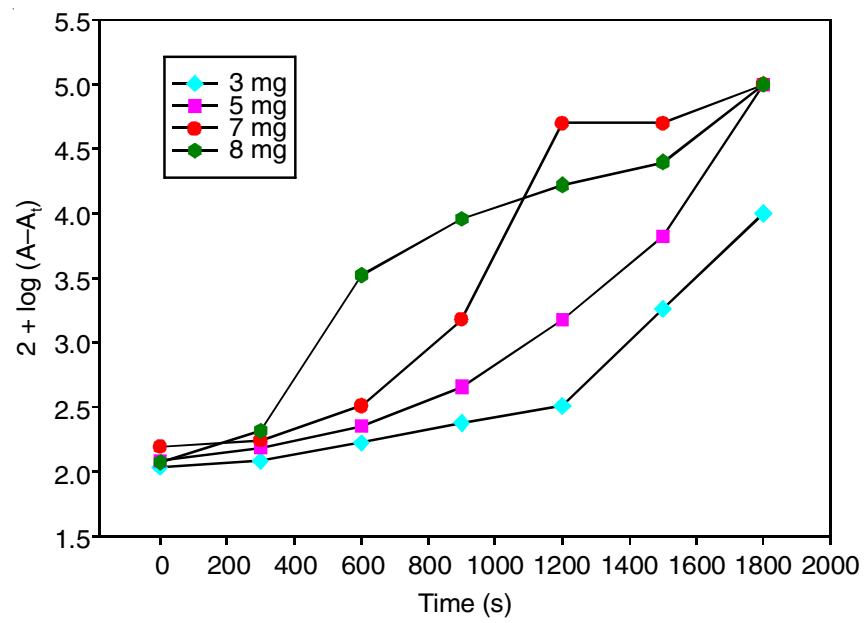

Fig. 5. Plot of $2+\log \left(A-A_{t}\right) v s$. time 


\begin{tabular}{cccc}
\hline \multicolumn{4}{c}{ TABLE-3 } \\
\hline$[\mathrm{Rh}-\mathrm{B}](\mathrm{mm})$ & {$\left[\mathrm{NaBH}_{4}\right](\mathrm{mm})$} & {$[$ Catalyst $](\mathrm{mg})$} & $\mathrm{K}_{\mathrm{obs}} \times 10^{-3}\left(\mathrm{~s}^{-1}\right)$ \\
\hline 1.0 & 100 & 3 & 1.0686 \\
1.0 & 100 & 5 & 1.6815 \\
1.0 & 100 & 7 & 2.3915 \\
1.0 & 100 & 8 & 3.5000 \\
\hline
\end{tabular}

\begin{tabular}{cccc}
\multicolumn{5}{c}{ TABLE-4 } \\
\hline$[\mathrm{MG}](\mathrm{mm})$ & {$\left[\mathrm{NaBH}_{4}\right](\mathrm{mm})$} & {$[$ Catalyst $](\mathrm{mg})$} & $\mathrm{K}_{\mathrm{obs}} \times 10^{-3}\left(\mathrm{~s}^{-1}\right)$ \\
\hline 1.0 & 60 & 5 & 0.5257 \\
1.0 & 80 & 5 & 0.5900 \\
1.0 & 100 & 5 & 1.3714 \\
1.0 & 110 & 5 & 1.6257 \\
\hline
\end{tabular}

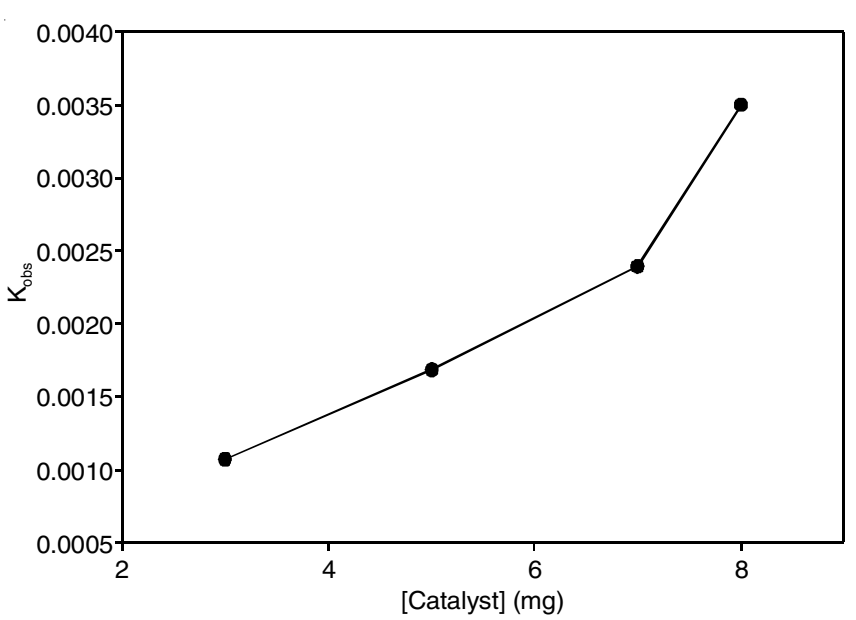

Fig. 6. $\mathrm{K}_{\mathrm{obs}} v s$. [catalyst]

\section{Kinetic study for the reduction of malachite green using} graphene oxide supported Ru-Ag NPs catalyst

Effect of $\left[\mathrm{NaBH}_{4}\right]$ : The reduction of malachite green was studied by varying the concentration of $\mathrm{NaBH}_{4}$ in the range from 60 to $110 \mathrm{~mm}$ by keeping the other parameters as constants. From the plot, $2+\log \left(\mathrm{A}-\mathrm{A}_{\mathrm{t}}\right) v s$. time, the pseudo-first order rate constants were evaluated and presented in Fig. 7. The observed rate constants increased with the increase in the concentration of $\mathrm{NaBH}_{4}$ as shown in Table-4 and the corresponding plots was depicted in Fig. 8. As the concentration of $\mathrm{NaBH}_{4}$ raises, the adsorption of $\mathrm{BH}_{4}$ - ions into the nanoparticle surfaces also increases, as a result, the relay of electrons from $\mathrm{BH}_{4}^{-}$(donor) to the malachite green (receptor) increases. It is worth to state that under the fixed concentration of $\mathrm{NaBH}_{4}$ the reduced product viz., organic dyes remains non-oxidized, since the liberated hydrogen eliminates the air hence prevents the oxidation.

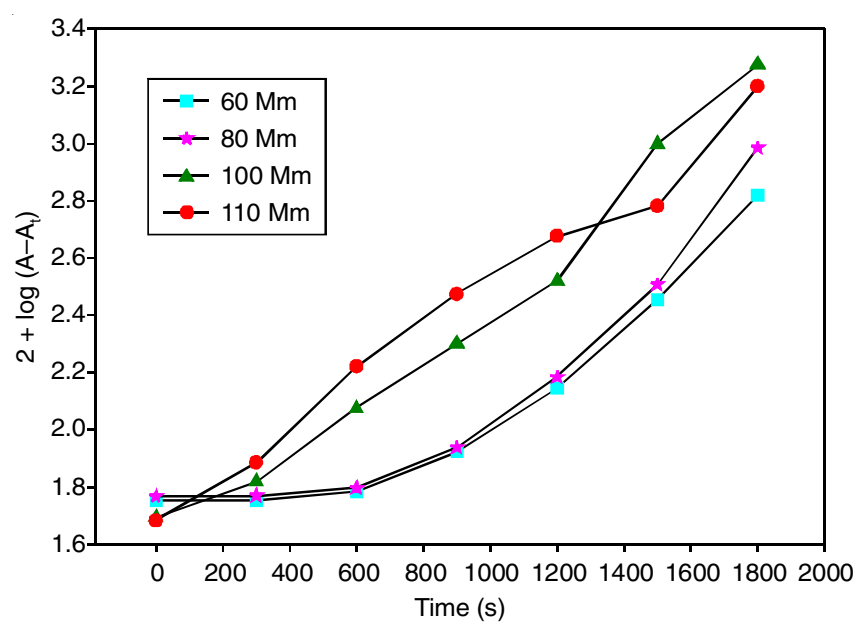

Fig. 7. Plot of $2+\log \left(A-A_{t}\right) v s$. time

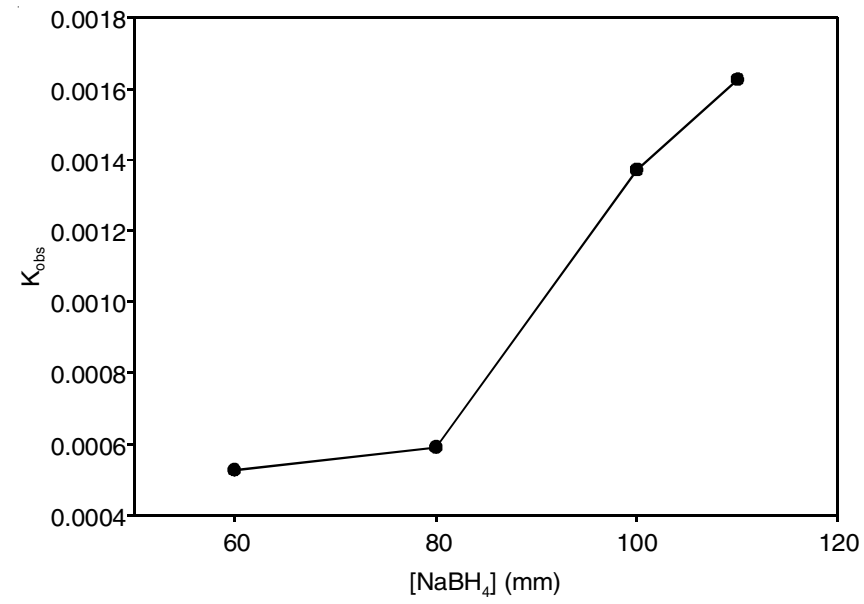

Fig. 8. $\mathrm{K}_{\text {obs }}$ vs. $\left[\mathrm{NaBH}_{4}\right]$

Effect of [catalysts]: Similarly, in the case of change in the concentration of the catalyst, the $\mathrm{k}_{\mathrm{obs}}$ were found to increases with respect to the concentration of catalyst irrespective of organic dyes used. The effect of GO-Ru-Ag NPs, was performed by varying the concentration of the catalyst from 2 to $7 \mathrm{mg}$ which is shown in Fig. 9, keeping the other parameters constant. The plot derived from observed rate constant against the amount of catalyst was shown in Table-5. From this plot, it has been understood that the amount of catalyst and the rate constant are parallel to each other are given in Fig. 10. It has been obviously known fact, that at higher concentration of the

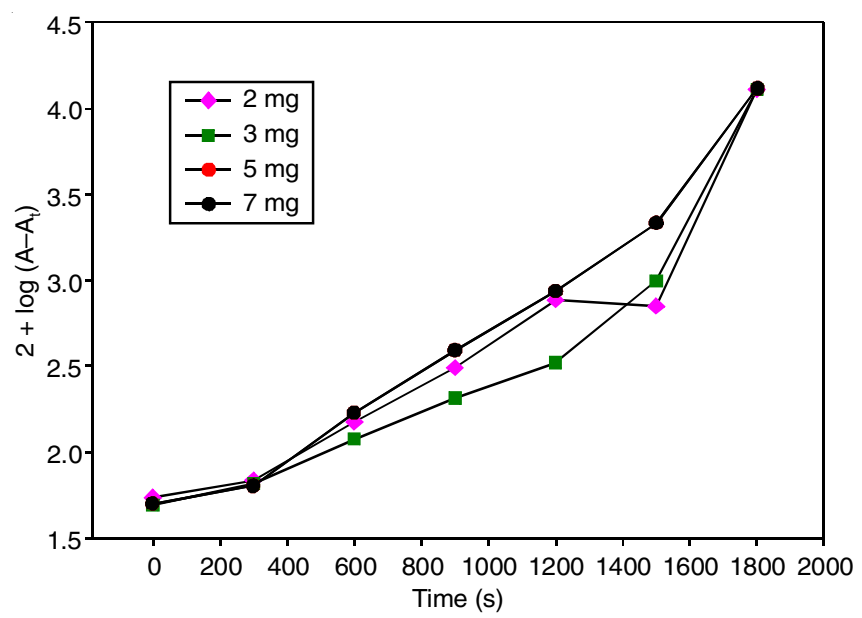

Fig. 9. Plot of $2+\log \left(\mathrm{A}-\mathrm{A}_{\mathrm{t}}\right) v s$. time

\begin{tabular}{cccc}
\multicolumn{4}{c}{ TABLE-5 } \\
\hline$[\mathrm{MG}](\mathrm{mm})$ & {$\left[\mathrm{NaBH}_{4}\right](\mathrm{mm})$} & {$[$ Catalyst $](\mathrm{mg})$} & $\mathrm{K}_{\mathrm{obs}} \times 10^{-3}\left(\mathrm{~s}^{-1}\right)$ \\
\hline 1.0 & 100 & 2 & 1.4440 \\
1.0 & 100 & 3 & 1.7243 \\
1.0 & 100 & 5 & 1.8728 \\
1.0 & 100 & 7 & 2.2143 \\
\hline
\end{tabular}




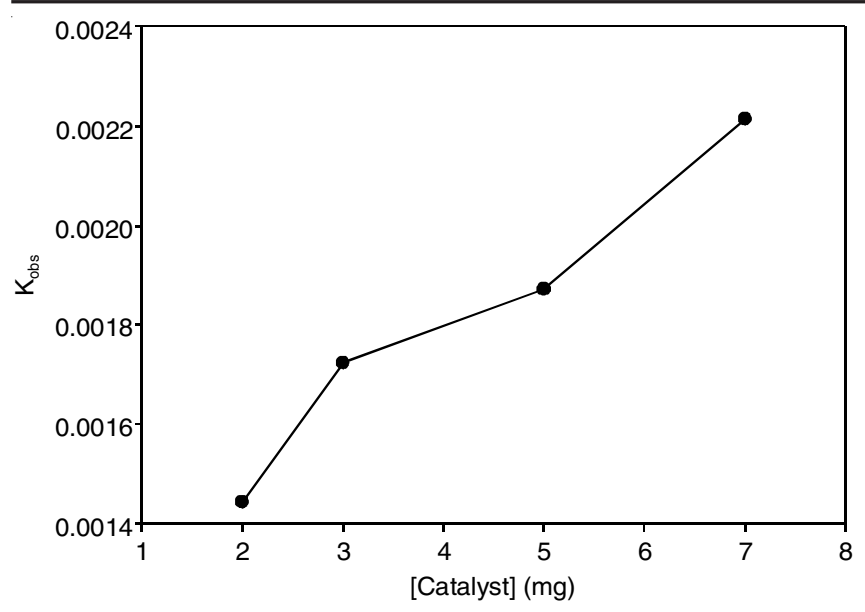

Fig. 10. $\mathrm{K}_{\mathrm{obs}} v s$. [catalyst]

catalyst, the active sites of nanoparticles is also high that enhances the rate constant.

\section{Conclusion}

The discolouration of rhodamine $\mathrm{B}$ and malachite green is also a pseudo first order with respect to rhodamine B, malachite green and sodium borohydride. The discolouration increases with temperature, the observed rate constants increased with the increase in the concentration of $\mathrm{NaBH}_{4}$. Kinetic study for the reduction of organic dye using graphene oxide supported Ru-Ag NPs catalyst single step process, economic viability; effective and rapid production of nanoparticles could be used to biomedical and environmental applications.

\section{CONFLICT OF INTEREST}

The author declare that there is no conflict of interests regarding the publication of this article.

\section{REFERENCES}

1. H. Mcheik and M.M. El Jamal, J. Chem. Technol. Metall., 48, 357 (2013).

2. S. Wang and Z.H. Zhu, Dyes Pigments, 75, 306 (2007); https://doi.org/10.1016/j.dyepig.2006.06.005.

3. E.R. Nestmann, G.R. Douglas, T.I. Matula, C.E. Grant and D.J. Kowbel, Cancer Res., 39, 4412 (1979).

4. V.K. Gupta and Suhas, J. Environ. Manage., 90, 2313 (2009); https://doi.org/10.1016/j.jenvman.2008.11.017.

5. L. Fu, Y. Zheng, Q. Ren, A. Wang, B. Deng, J. Ovonic Res., 11, 21 (2015).

6. P. Saikia, A.T. Miah and P.P. Das, J. Chem. Sci., 129, 81 (2017); https://doi.org/10.1007/s12039-016-1203-0.
7. B.K. Ghosh, S. Hazra, B. Naik and N.N. Ghosh, Powder Technol., 269, 371 (2015); https://doi.org/10.1016/j.powtec.2014.09.027.

8. N. Gupta, H.P. Singh and R.K. Sharma, J. Mol. Catal. Chem., 335, 248 (2011);

https://doi.org/10.1016/j.molcata.2010.12.001.

9. K. Mallick, M.J. Witcomb and M.S. Scurrell, Appl. Phys. A Mater., 80, 797 (2005); https://doi.org/10.1007/s11051-006-9104-7.

10. M.M. Khan, J. Lee and M.H. Cho, J. Ind. Eng. Chem., 20, 1584 (2014); https://doi.org/10.1016/j.jiec.2013.08.002.

11. M.M. Khan, S. Kalathil, T.H. Han, J. Lee and M.H. Cho, J. Nanosci. Nanotechnol., 13, 6079 (2013); https://doi.org/10.1166/jnn.2013.7666.

12. J. Chanathaworn, C.Bunyakan, W. Wiyaratn and J. Chungsiriporn, Songklanakarin J. Sci. Technol., 34, 203 (2012).

13. A. Sugunan and J. Dutta, Nanotechnology, 2, 125 (2008); https://doi.org/10.1002/9783527628155.nanotech013.

14. F.D. Mai, C.C. Chen, J.L. Chen and S.C. Liu, J. Chromatogr. A, 1189, 355 (2008); https://doi.org/10.1016/j.chroma.2008.01.027.

15. J.J. Vora, S.K. Chauhan, K.C. Parmar, S.B. Vasava, S. Sharma and L.S. Bhutadiya, E-J. Chem., 6, 531 (2009); https://doi.org/10.1155/2009/139753.

16. S. Liu, C. Li, J. Yu and Q. Xiang, CrystEngComm, 13, 2533 (2011); https://doi.org/10.1039/c0ce00295j.

17. F. Barka-Bouaifel, B. Sieber, N. Bezzi, J. Benner, P. Roussel, L. Boussekey, S. Szunerits and R. Boukherroub, J. Mater. Chem., 21, 10982 (2011); https://doi.org/10.1039/c1jm11351h.

18. M.A. Kanjwal, N.A.M. Barakat, F.A. Sheikh, S.J. Park and H.Y. Kim, Macromol. Res., 18, 233 (2010); https://doi.org/10.1007/s13233-010-0303-9.

19. K. Byrappa, A.K. Subramani, S. Ananda, K.M.L. Rai, R. Dinesh and M. Yoshimura, Bull. Mater. Sci., 29, 433 (2006); https://doi.org/10.1007/BF02914073.

20. P. T. Yin, S. Shah, M. Chhowalla and K.B. Lee, Chem. Rev., 115, 2483 (2015); https://doi.org/10.1021/cr500537t.

21. Q.I. Rahman, M. Ahmad, S.K. Misra and M. Lohani, Mater. Lett., 91, 170 (2013); https://doi.org/10.1016/j.matlet.2012.09.044.

22. K. Yu, S. Yang, H. He, C. Sun, C. Gu and Y. Ju, J. Phys. Chem. A, 113, 10024 (2009); https://doi.org/10.1021/jp905173e.

23. M. Cotto-Maldonado, Am. Chem. Sci. J., 3, 178 (2013); https://doi.org/10.9734/ACSJ/2013/2712.

24. M. Sun, D. Li, Y. Chen, W. Chen, W. Li, Y. He and X. Fu, J. Phys. Chem. C, 113, 13825 (2009); https://doi.org/10.1021/jp903355a.

25. S. Rajalakshmi, S. Pitchaimuthu, N. Kannan, and P. Velusamy, Appl. Water. Sci., 7, 115 (2014); https://doi.org/10.1007/s13201-014-0223-5.

26. P. Andal, C. Loganayagi and Roopakala, Res. J. Pharm. Technol., 10, 3610 (2017); https://doi.org/10.5958/0974-360X.2017.00656.4. 